Paraplegie amyotrophique lentement ascendante, d'abord spasmodique, puis flasque, s'accompagnant de dissociation albuminocytologique. Revue Neurol (Paris) 1926;33 (2): 1-42.

${ }^{2}$ Aminoff MJ. Spinal Angiomas, Oxford: Blackwell, 1976:82-85.

${ }^{3}$ Antoni N. Spinal vascular malformations (angiomas) and myelomalacia. Neurology (Minneap) 1962; 12:895-904.

${ }^{4}$ Greenfield JG, Turner JWA. Acute and subacute necrotic myelitis. Brain 1939; 62:227-52.

${ }^{5}$ Hughes JT. Pathology of the Spinal Cord, 2nd Edition, London: Lloyd-Luke, 1978:81-83.

6 Jellinger K. Pathology of spinal vascular malformations and vascular tumours. In: Pia HW, Djindjian R, eds. Spinal Angiomas. Advances in Diagnosis \& Therapy. Berlin: Springer-Verlag (1978): 18-44.

Accepted 6 August 1984

\section{Cephalic tetanus presenting with Bell's palsy}

Sir: Cephalic tetanus is a clinical variant characterised by paralysis of the cranial nerves. ${ }^{1-5}$ Weakness of the muscles innervated by the seventh nerve is the most frequently reported symptom. However, cephalic tetanus commencing with facial paralysis, as in the case described here, is unusual.

A 53-year-old man suffered a wound on the right side of his chin, caused by a stick. Two days later, there was inflammation at the site of the injury and weakness of the right orbicularis oris muscle. Later the paralysis increased, with weakness of the ipsilateral orbicularis oculi, but without facial stiffness. On the fifth day, the patient was seen by his general practitioner who diagnosed right-sided Bell's palsy and prescribed prednisone $15 \mathrm{mg}$ daily. Five days later, the patient had difficulty in swallowing and in opening his mouth, and was referred to our hospital. Examination revealed severe lockjaw and left facial hemispasm, combined with right facial paralysis, predominantly affecting the lower portion (fig). Taste was not affected. The wound was infected. Treatment included debridement of the wound, tracheotomy, penicillin, antitetanic gamma globulin, tetanus toxoid and diazepam. At rest, the electromyogram showed bilateral continuous abnormal activity in the masseters, orbicularis oris and orbicularis oculi muscles; electrical silence was not obtained. The patient began to improve three days after admission, being asymptomatic three months later. A further EMG study after 33 days evolution showed a clear reduction in spontaneous activity and a normal blink reflex.

Facial palsy in the course of cephalic tetanus usually appears when there is already evidence of trismus ${ }^{3578}$ or simultaneously with it. ${ }^{469-11}$ Thus the interest in our case lies in the fact that facial paralysis was the only clinical sign for the first eight days of evolution, being diagnosed understandably as Bell's palsy. Although mistaken diagnoses of facial paralysis at the onset of cephalic tetanus have been mentioned occasionally, ${ }^{212}$ the pattern of evolution described here has only been reported in one case. ${ }^{10}$ This was a 14year-old patient who developed left facial paralysis 3 days after suffering an eye injury on the same side; trismus and dysphagia were present the following day. Our EMG findings are consistent with those previously described.23511 Consequently, when Bell's palsy and craniofacial injury are found together, the possibility of cephalic tetanus should be considered.

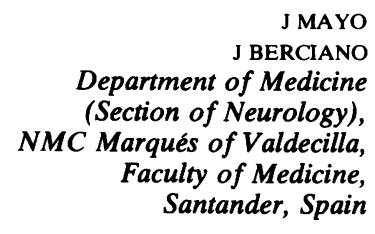

J MAYO

J BERCIANO

Department of Medicine (Section of Neurology), Faculty of Medicine, Santander, Spain

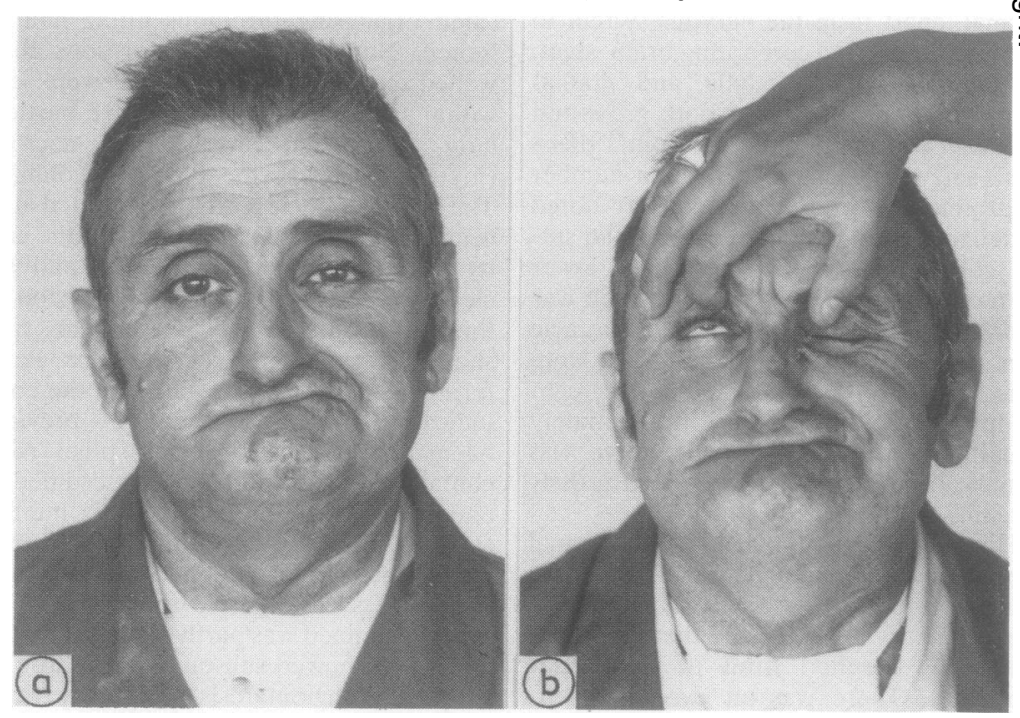

Fig Patient 20 days after onset of symptoms. Note the healed wound on the right side of the chin, right peripheral facial palsy and spasm of the left orbicularis oris and orbicularis oculi muscles.

\section{References}

' Boudouresques J, Khalil R, Vigouroux RA Daniel F, Goset A. Infectious diseases of nerves. In: Vinken PJ, Bruyn GW, eds心 Handbook of Clinical Neurology. Vol 7든 Amsterdam: North Holland Publishing Company, 1970:473-494.

2 Vakil BJ, Singhal BS, Pandya SS, Irani PF尔 Cephalic tetanus. Neurology (Minneap $\Omega$ 1973;23:1091-1096.

${ }^{3}$ Dastur FC, Shanani MT, Dastoor DH, et al Cephalic tetanus: demonstration of a dual lesion. J Neurol Neurosurg Psychiatri
1977;40:782-6.

${ }^{4}$ Farquharson RG. Cephalic tetanus. Proc R So드 Med 1972;65:875-6.

s García Mullin R, Daroff RB. Electrophysiolog $\frac{\overline{\bar{\tau}}}{\mathrm{s}}$ ical investigations of cephalic tetanus. Neurol Neurosurg Psychiatry 1973;36으 296-301.

- Abde VW, Dekate MP. Cephalic tetanus (clinical analyses of 9 cases). J Indian Med Assoc $\vec{O}$ 1980;74:111-3.

${ }^{7}$ Mishra M, Sinha BN. Facial palsy in tetanus $\overrightarrow{\vec{\omega}}$

${ }^{8}$ Ahuja GK, Kamala G. Cephalic tetanus Neurol India 1978;26:10-13.

${ }^{9}$ Bagratuni L. Cephalic tetanus with report of a case. Br Med J 1952;1:461-3.

${ }^{10}$ Park DM. Cranial nerve palsies in tetarmis cephalic tetanus. J Neurol Neuros सुg Psychiatry 1970;33:212-5.

"Mamoli B, Ludin HP. Electrophysiologecab investigations in a case of cephalic tetanu $D$ Neurol 1977;214:251-5.

${ }_{12}$ Struppler A, Struppler E, Adams RD. LoeaK

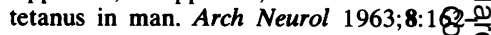
78.

Accepted 6 August 1984 Br Med J 1972;3:475-6. 